Revista de
Economild
Contemporâned

\title{
ANÁLISE DA FUSÃO AZUL-TRIP SOB A ÓTICA DOS GANHOS DE EFICIÊNCIA
}

\author{
Kleber Pacheco de Castro \\ Lucia Helena Salgado e Silva ${ }^{b}$ \\ Alexandre Marinho ${ }^{c}$
}

${ }^{a}$ Economista e estudante de doutorado do Programa de Pós-Graduação em Ciências Econômicas da Universidade do Estado do Rio de Janeiro (PPGCE/UERJ). Rio de Janeiro, RJ, Brasil. ORCID: https:// orcid.org/0000-0002-3451-2659.

bProfessora associada da Faculdade de Ciências Econômicas da Universidade do Estado do Rio de Janeiro

(FCE/UERJ). Rio de Janeiro, RJ, Brasil. ORCID: https://orcid.org/0000-0001-6538-2626.

'Técnico de Planejamento e Pesquisa do Instituto de Pesquisa Econômica Aplicada (IPEA) e professor associado da Faculdade de Ciências Econômicas da Universidade do Estado do Rio de Janeiro (FCE/

UERJ). Rio de Janeiro, RJ, Brasil. ORCID: https://orcid.org/0000-0001-9152-3584.

Artigo recebido em 12/01/2018 e aceito para publicação em 07/12/2018.

RESUMO: Este artigo objetivou fazer uma avaliação da fusão entre as companhias aéreas Azul e Trip, mensurando os potenciais ganhos de eficiência decorrentes do ato de concentração. Modelos de análise envoltória de dados (DEA), conjuntamente com a técnica de reamostragem denominada bootstrap, foram utilizados como instrumentos para obter essa mensuração. Os resultados mostraram que os ganhos de eficiência decorrentes da fusão são muito pequenos; uma combinação da aplicação com a teoria mostra que os ganhos podem ser negativos; os efeitos de escala não atuam em favor da fusão, enquanto os efeitos de aprendizado atuam em favor da fusão; os ganhos obtidos poderiam ocorrer mesmo sem a fusão (individualmente).

PALAVRAS-CHAVE: fusão; aviação; transporte; DEA; eficiência.

CÓDIGOS JEL: L40; L93; C60.

Correspondência para: Kleber Pacheco de Castro

Contato: kleberpcastro@gmail.com 


\title{
ANALYSIS OF THE MERGER BETWEEN AZUL \& TRIP UNDER THE OPTICS OF THE EFFICIENCY GAINS
}

\begin{abstract}
This article aimed to evaluate the merger between the airlines Azul and Trip, measuring the potential efficiency gains from the act of concentration. Data envelopment analysis (DEA) models, in conjunction with the resampling technique called bootstrap, were used as instruments for this measurement. The results showed that: the efficiency gains resulting from the merger are very small; a combination between the application and the theory shows that the gains could be negative; the effects of scale do not work in favor of the merger, while the learning effects works in favor of the merger; the gains could occur in isolation (individually).
\end{abstract}

KEYWORDS: fusion; aviation; transport; DEA; efficiency. 


\section{INTRODUÇÃO}

Em 2012 o setor de aviação civil comercial brasileiro tornou-se ainda mais concentrado com o anúncio da fusão entre as companhias aéreas Azul e Trip. Detendo, respectivamente, a terceira e a quarta colocações na participação de mercado doméstico, as empresas inicialmente alegaram, na defesa do ato de concentração, que juntas poderiam exercer maior pressão competitiva sobre as líderes de mercado (TAM e GOL), além de oferecerem uma maior gama de localidades atendidas com maior frequência, o que seria possível devido à complementaridade de suas malhas aéreas.

$\mathrm{O}$ ato de concentração entre as referidas companhias aéreas foi submetido ao Conselho Administrativo de Defesa Econômica ${ }^{1}$ (CADE) no mesmo ano, tendo sido aprovado em março de 2013, com a restrição de que o acordo de codeshare entre Trip e TAM fosse encerrado. A forte concentração da nova empresa "Azul-Trip" em algumas rotas, especialmente no mercado regional, não foi percebida como danosa pelo CADE, de acordo com entendimento de que se tratariam de "mercados contestáveis".

O objetivo desse artigo é fazer uma nova análise dessa fusão, apresentando uma contestação teórica e empírica ao entendimento do CADE e, primordialmente, avaliando os ganhos de eficiência decorrentes do ato de concentração. Para isso, será utilizado o instrumental não paramétrico da Análise Envoltória de Dados (Data Envelopment Analysis DEA). O foco da análise aqui é voltado apenas para o transporte de passageiros, sendo deixada de lado a atividade de transporte de cargas e correios. Tal escolha se justifica pela importância do transporte de pessoas na composição das receitas das empresas aéreas no Brasil, que chegou a quase $84 \%$ do total em 2016, segundo a ANAC (2017). Essa abordagem é inédita na literatura nacional, e aponta para os eventuais custos e benefícios econômicos causados pela fusão.

Além desta introdução, o artigo está dividido em mais seis seções: na segunda seção há uma breve avaliação teórica da decisão do CADE; a terceira seção fará uma revisão da literatura sobre a análise das decisões das autoridades sobre atos de concentração, causa e efeito do movimento de concentração da indústria de aviação civil e aplicação da DEA em análises de fusão; a quarta seção trará a apresentação dos modelos DEA utilizados para estimar o ganho de eficiência com o ato de concentração; a quinta seção terá um cunho metodológico, mostrando as fontes dos dados e as simulações selecionadas; a sexta seção apresentará os resultados obtidos a partir dos modelos DEA e indicará tendências gerais das simulações; e, por fim, a sétima seção trata das considerações finais do trabalho.

1 Ato de Concentração nº 08700.004155/2012-81. 


\section{BREVE CONSIDERAÇÃO SOBRE A DECISÃO DO CADE}

A decisão do CADE sobre a fusão entre Azul e Trip tem seu foco de análise direcionado para o eventual poder de mercado, decorrente do ato de concentração, nos mercados relevantes (rotas específicas). Apesar da assunção de que a nova companhia resultante da fusão teria domínio em determinadas rotas, a decisão aponta que:

[...] para empresas já atuantes no país, a entrada em uma nova rota (ou expansão de uma rota operada) é viável, desde que não haja restrições relevantes de infraestrutura nos aeroportos afetados. Essa flexibilidade de organização da malha é ainda maior para as empresas de maior porte e que possuam maior frota, como é o caso das líderes TAM e GOL. (CADE, 2012, p. 51)

A partir dessa hipótese, a análise feita na referida decisão é centrada na capacidade operacional dos aeroportos envolvidos nas rotas em que haveria alguma concentração em poder da nova companhia. A conclusão do CADE a respeito dos aeroportos é de que em todos os aeroportos analisados há slots disponíveis em todas as faixas de horários e todos os dias da semana. Em outras palavras, haveria capacidade instalada disponível nos aeroportos para atender a empresas entrantes em determinado mercado (rota).

Apesar de não haver menção explícita do termo ao longo da decisão do CADE, há uma clara relação entre as conclusões deste e a teoria dos mercados contestáveis (BAUMOL, PANZAR e WILLIG, 1982). Essa teoria mostra que, em determinados mercados, é possível haver um equilíbrio competitivo com poucas firmas operando. Essa situação é possível quando existem entrantes potenciais para um mercado com as seguintes características: inexistência de barreiras à entrada, inexistência de economias de escala, inexistência de custos afundados (sunkcosts) e fácil acesso à tecnologia disponível para incumbentes e entrantes.

Tradicionalmente o mercado de aviação civil é apontado como um caso particularmente relevante de mercado contestável (BAILEY e PANZAR, 1981), tendo sua aplicação focada nessa indústria (CHURCH e WARE, 2000).

Para Kwoka (2008), não por acaso, todas as fusões do setor aéreo americano foram aprovadas até o final da década de 1980 - momento a partir do qual a teoria dos mercados contestáveis deixou de servir de base para a análise de fusões no mercado de aviação civil americano (KATZ, 2002).

De acordo com Fawcett e Ferris (1989), as empresas incumbentes na década de 1980, quando se depararam com um mercado competitivo desregulamentado, passaram a atuar no sentido de reduzir o impacto da concorrência (potencial), derrubando as bases que sustentavam a teoria dos mercados contestáveis, como, por exemplo, 
criando barreiras à entrada (físicas, informacionais e de capital). Goetz (2002) também orienta sua crítica aos fundamentos da teoria, afirmando que as empresas incumbentes têm economias de escala; algumas tecnologias não são acessíveis às empresas entrantes; há barreiras à entrada na forma de dificuldade para aquisição de espaço de portão no aeroporto, aumento do custo de operações aeroportuárias, custos de publicidade e marketing, e outros custos associados à competição contra uma firma maior e mais estabelecida. Em resumo:

Não há dúvida de que entrar no mercado de rotas aéreas é mais fácil do que entrar em muitos outros mercados, uma vez que o capital crucial - a aeronave - pode ser redistribuído com relativa rapidez de uma rota para outra. Mas a questão crucial não é se algum capital é fungível, mas se os custos irrecuperáveis são tais a ponto de constituírem relevantes obstáculos à entrada. Atualmente considera-se ser este amplamente o caso. [...] a infraestrutura em terra das companhias aéreas, como portões de embarque, áreas de terminais, de despacho de bagagem etc., pode representar relevante barreira à entrada em um aeroporto e, portanto, a uma rota. Além disso, as companhias aéreas incumbentes com frequência levantam uma variedade de obstáculos à entrada na forma de sistemas computadorizados de reservas que favorecem a si mesmas, estruturas de comissão de agentes de viagem que dirigem o movimento para os incumbentes, e muitos programas de fidelização, que criam obstáculos às companhias menores ou mais novas. Todos esses fatores ajudam a proteger os incumbentes da ameaça de entrada. (KWOKA, 2008, p. 43)

Assim, o Departamento de Justiça americano e a Comissão Federal de Comércio (Federal Trade Commission - FTC) passaram a questionar a teoria que até então era predominante e estabeleceram outras diretrizes em seus guidelines, mais parecidas com as análises de fusões de outros setores. Tal orientação não parece guiar a decisão do CADE no caso "Azul-Trip".

\section{REVISÃO DE LITERATURA}

Inspiram o presente trabalho três linhas de pesquisa: (i) a análise da eficácia de decisões de autoridades concorrenciais em casos de fusão e concentração; (ii) os estudos sobre causas e efeitos da concentração na indústria de aviação civil sobre tarifas, oferta e qualidade de serviço; e (iii) os estudos sobre eficiência relativa, com uso da mesma metodologia aqui proposta, para casos de fusão e concentração. 
A análise da eficácia de decisões em defesa da concorrência (ou antitruste) compõe um gênero mais amplo de estudos, envolvendo a avaliação de políticas públicas, motivadas -como aqui - pelo intuito de colaborar para aprimorá-las no alcance de seus objetivos.

Para a avaliação da eficácia da política de defesa da concorrência há diversas metodologias disponíveis e já testadas; as mesmas metodologias podem ser utilizadas para guiar ex-ante decisões baseadas em evidências (NEVO e WHISTON, 2010; BJORNERSTEDT e VERBOVEN, 2013). A contribuição do presente trabalho está em aplicar a metodologia de DEA ao exame de efeitos de fusão aprovada pela autoridade brasileira em defesa da concorrência, efeitos esses sobre eficiência relativa, fator chave para a decisão da autoridade pela aprovação ou não de um ato de concentração (fusão ou aquisição). ${ }^{2}$

Até o presente, a metodologia DEA - a par de sua utilização recente para o exame de fusões ocorridas na indústria bancaria (em outras jurisdições) - não foi incorporada ao exame de eficiências - potenciais ou efetivadas - em decisões nacionais. Assim, procuramos demonstrar como a utilização da técnica de DEA pode ser agregada ao rol de metodologias capazes de permitir a análise da eficácia de decisões tomadas pela autoridade antitruste, além de auxiliar o processo de tomada de decisão baseada em evidências - metodologias essas levantadas e descritas por Silva e De Souza (2016). Tais metodologias são, em uma linha: modelos estruturais e simulações; métodos de efeitos de tratamento e estudos de eventos.

A escolha do caso para aplicação da metodologia DEA não foi aleatória, mas sim seguiu a orientação de Farrell, Pautler e Vita (2000), para quem, quando se busca avaliar o rigor de uma decisão é necessário “[...] focar em fusões na margem, justamente os casos polêmicos, fusões que de modo plausível poderiam ser consideradas anticompetitivas ou quase isso, mas que não foram bloqueadas por uma variedade de razões idiossincráticas" (SILVA e DE SOUZA, 2016, p. 5).

Por outro lado, efeitos e determinantes de fusões e aquisições na indústria de aviação civil vêm sendo bastante examinados em virtude da possibilidade de (e interesse na) comparação antes/depois, proporcionados pelos processos de desregulamentação tanto nos EUA quanto no Brasil em décadas recentes. Borenstein (1989) foi pioneiro nessa análise, focada na relação entre concentração (na indústria e por aeroportos), rotas e preços (tarifas), no que foi seguido por Evans e Kessides (1993) e Bilotkach e Lakew (2014).

2 Considerando que os proponentes de fusões e aquisições unanimemente alegam a realização de ganhos de eficiência (em particular de escala) como a motivação e justificativa para a operação. 
Com relação à motivação econômica para a concentração nesses mercados, Brueckner e Spiller (1994) encontram determinantes de custos (nomeadamente, economias de densidade de tráfego) para o aumento da concentração tanto por aeroportos quanto na indústria como um todo (também nos Estados Unidos). Oliveira e Oliveira (2017) desenvolvem modelo econométrico para capturar relação entre concentração de mercado por pares de cidades no mercado brasileiro de 2002 a 2013. Testam a hipótese da associação entre concentração e tamanho de mercado (levantada por BRUECKNER e SPILLER, 1994) e a hipótese de concentração associada à estratégia de qualidade de serviço e investimento em capacidade, como em Spence (1977), Dixit (1979) e Cohen e Mazzeo (2004). Confirmam a crítica ao paradigma estrutura-conduta-desempenho feita por Demsetz (1973 e 1974), dada a endogeneidade da relação entre as variáveis.

Werden, Joskow e Johnson (1991) estimaram efeitos de duas fusões na indústria de aviação civil aprovadas pelo Departamento de Transporte norte-americano (DOT) e questionadas pelo Departamento de Justiça (DOJ) nos anos 1980. Comparando o desempenho antes e depois das companhias envolvidas, identificaram, tanto para fusão TWA-Osark como para a fusão Northwest-Republic, aumento de tarifas e redução significativa de oferta de vôos entre pares de cidade a partir, respectivamente dos hubs Saint Louis e Minneapolis.

O método DEA tem sido utilizado para o exame de fusões horizontais no mercado financeiro, como em Garden e Ralston (1999). As autoras examinaram os efeitos sobre eficiência em fusões de uniões de crédito (credit unions) australianas ocorridas no período 1993/1994. A abordagem de fronteira DEA foi utilizada para se obter medidas de "eficiência-x" (LEIBENSTEIN, 1966) e eficiência alocativa. Os resultados forneceram evidências estatísticas de que, em média, tais fusões não levaram ao aumento de eficiência nas duas dimensões, se comparadas a outras companhias de crédito.

Outro estudo na mesma linha (HALKOS e TZEREMES, 2013) propõe o uso do procedimento baseado em DEA bootstrapped para avaliar ex-ante os ganhos de curto prazo de eficiência operacional em fusões e aquisições bancárias propostas na Grécia no período 2007-2011. Os resultados revelam que, comparando o período de um ano antes-um ano depois da eclosão da crise fiscal grega, a maioria das fusões e aquisições bancárias (potenciais) examinadas seria incapaz de gerar ganhos de eficiência no curto prazo. Ainda, os resultados para operações, mesmo entre bancos previamente eficientes, não asseguravam como resultante um banco eficiente.

Finalmente, Avkiran (1999) aplica o método DEA para examinar ganhos de eficiência operacional, produtividade do trabalho, desempenho em lucros e eficiência relativa média de bancos comerciais australianos no período de 1986 a 1995. Mudanças no marketshare dos bancos, medidos por volume de depósitos, são usados para se 
verificar em que medida eventuais ganhos de eficiência são transferidos para o público. Os resultados empíricos confirmam o pressuposto de que os bancos adquirentes são mais eficientes do que os adquiridos, contudo nem sempre a nova entidade apresenta os mesmos níveis de eficiência do período pré-fusão. Quanto ao compartilhamento de benefícios, os resultados são ambíguos.

Tais estudos sobre mercado bancário com o uso da metodologia aqui proposta sugerem o quão promissor pode ser buscar ampliar o uso do método para a análise de fusões em outras indústrias e incorporá-lo como mais uma ferramenta na análise em defesa da concorrência, seja para o exame ex-post do efeito de decisões, seja como insumo para a decisão ex-ante.

O presente trabalho, portanto, contribui para expandir o uso desse instrumental metodológico para o exame do impacto da eficiência (potencial ou efetiva) gerada ou esperada - em operações de fusão e aquisição examinadas pela autoridade de defesa da concorrência.

\section{ANÁLISE ENVOLTÓRIA DE DADOS}

A Análise Envoltória de Dados (Data Envelopment Analysis - DEA) é um método matemático, derivado da programação linear, que permite estimar medidas de eficiência de "unidades tomadoras de decisão" (Decision Making Unit - DMU). A eficiência, nesse caso, é um conceito relativo e que deve ser entendido como o que foi produzido com relação ao que poderia ter sido produzido, dada a disponibilidade de recursos (MELLO et al., 2005).

A ideia básica desse instrumental - que tem sua base no trabalho de Farrell (1957) - é comparar a produtividade (outputs/inputs) de diversas DMU, para que assim seja possível estabelecer uma "fronteira de possibilidade tecnológica", a qual seria composta pelas DMU mais produtivas e, consequentemente, eficientes. O nível de eficiência das demais DMU seria obtido a partir da distância destas para a fronteira. Inicialmente essa distância pode ser obtida a partir de uma orientação de minimização de inputs (para um dado nível de output, verifica-se o quão maior é o consumo de inputs de uma DMU com relação à fronteira) ou de maximização de outputs (para um dado nível de input, verifica-se o quão menor é a geração de outputs de uma DMU com relação à fronteira).

A possibilidade de se trabalhar com diversos inputs e diversos outputs é uma das principais vantagens da DEA. Nesses casos, os modelos fazem uma agregação deles em apenas um input "virtual” e um output "virtual". Essa agregação se dá em um problema de programação linear que maximiza a eficiência de cada DMU, atribuindo os pesos mais favoráveis possíveis aos insumos e produtos de cada unidade. 
De acordo com Marques e Silva (2006), outras vantagens da DEA são: adotar os melhores resultados como referências para comparação; não admitir uma forma paramétrica para a fronteira ou para a ineficiência quando associada ao erro; e decompor a natureza da eficiência em várias componentes.

Particularmente, a DEA se reveste de especial interesse no problema que estamos analisando. Uma característica adicional muito importante dessa metodologia é a possibilidade de calcular os valores ótimos (targets) de cada um dos insumos (inputs) e de cada um dos produtos (outputs) de cada uma das DMU (e de eventuais agregações da amostra), permitindo calcular a diferença entre valor observado e o valor ótimo (potencial) do mercado ou setor sob análise. Esse tipo de análise permite estimar os excessos de utilização de insumos e as perdas de produto potencial. Até onde sabemos, a decisão do CADE passou ao largo da utilização de instrumentos modernos para esse tipo de avaliação. Aqui cabe ressaltar que, dados os elevados valores dos ativos, dos insumos e dos produtos da aviação civil, até mesmo pequenas perdas percentuais de produção ou pequenos percentuais de utilização em excesso de insumos serão traduzidos em valores financeiros muito elevados. Esse aspecto será discutido de modo exploratório em nossas considerações finais.

\subsection{PRINCIPAIS MODELOS DA DEA}

Dois textos seminais deram origem aos modelos mais populares dentro do escopo da DEA: o de Charnes, Cooper e Rhodes (1978) e o de Banker, Charnes e Cooper (1984). Esses dois trabalhos resultaram nos famosos modelos CCR e BBC, que diferem entre si, basicamente, pelo tipo de retorno de escala intrínseco ao modelo - enquanto no CCR adotam-se retornos constantes de escala (constant returns to scale - CRS), no BCC adotam-se retornos variáveis de escala (variable returns to scale - VRS). Sendo assim, a formulação básica da DEA é a mesma para ambos os casos, alterando-se apenas uma restrição entre um e outro. O modelo DEA input, ${ }^{3}$ orientado na forma da envoltória, ${ }^{4}$ é apresentado a seguir.

3 Qualquer modelo DEA também pode ser output orientado, isto é, pode priorizar a maximização de produto ao invés da minimização de insumos. Neste artigo optou-se por trabalhar apenas com modelos input orientado e, por isso, a formalização geral do modelo output orientado não será apresentada.

4 O modelo DEA pode ser apresentado por meio da forma da envoltória ou da forma dos multiplicadores. Neste artigo, apenas a forma da envoltória é disposta, uma vez que a segunda forma não foi necessária para a obtenção dos resultados. 
Seja uma unidade tomadora de decisões (DMU) que produz um vetor $y$ de outputs a partir de um vetor $x$ de inputs. Uma tecnologia $T$ é um conjunto de combinações de inputs e de outputs tal que $x$ pode produzir $y, T=\{(x, y) / x$ pode produzir $y\}$. Um modelo de DEA compreende o seguinte Programa de Programação Linear:

MinE

Sujeito a:

$$
\begin{gathered}
E x^{0} \geq \sum_{k=1}^{K} \lambda^{k} x^{k} \\
y^{0} \leq \sum_{k=1}^{K} \lambda^{k} x^{k} \\
\lambda \in \Lambda^{K}(\gamma)
\end{gathered}
$$

$E \rightarrow$ parâmetro de contração radial

$x^{0} \rightarrow$ vetor de inputs da DMU analisada

$x^{k} \rightarrow$ vetor de inputs da DMUk

$y^{0} \rightarrow$ vetor de outputs da DMU analisada

$y^{k} \rightarrow$ vetor de outputs da DMUk

$\lambda \rightarrow$ parâmetro de combinação de DMU seficientes

A diferença entre os modelos CCR (CRS) e BCC (VRS) se dá por meio do soma-

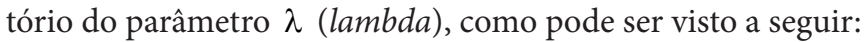

$$
\begin{gathered}
\lambda \in \Lambda^{K}(\mathrm{CRS})=\left\{\lambda \in \mathbb{R}_{+}^{K} \mid \sum_{k=1}^{K}=\text { livre }\right\} \\
\lambda \in \Lambda^{K}(\mathrm{VRS})=\left\{\lambda \in \mathbb{R}_{+}^{K} \mid \sum_{k=1}^{K} \lambda^{k}=1\right\}
\end{gathered}
$$

Além dos modelos CCR (CRS) e BCC (VRS), outros dois modelos também foram utilizados neste artigo: IRS (increasing returns to scale) e DRS (decreasing returns to scale). Da mesma forma que os dois primeiros, estes utilizam o mesmo modelo básico DEA, diferenciando-se apenas por meio das restrições:

$$
\begin{aligned}
& \lambda \in \Lambda^{K}(\mathrm{IRS})=\left\{\lambda \in \mathbb{R}_{+}^{K} \mid \sum_{k=1}^{K} \lambda^{k} \geq 1\right\} \\
& \lambda \in \Lambda^{K}(\mathrm{DRS})=\left\{\lambda \in \mathbb{R}_{+}^{K} \mid \sum_{k=1}^{K} \lambda^{k} \leq 1\right\}
\end{aligned}
$$


Há uma vasta literatura internacional que procura estimar os retornos de escala da indústria de transporte aéreo, focada no mercado norte-americano. O trabalho pioneiro nesse campo é atribuído a Caves (1962), que sugere que não há economias de escala significativas no setor antes do ato de desregulamentação de 1978 nos EUA. Após a desregulamentação, Caves, Christensen e Tretheway (1984) mantêm a evidência de poucas economias de escala, porém revelam a existência de economias de densidade, decorrente do tamanho da rede de ligações aéreas. Já Bailey e Williams (1988) revelam que os retornos de escala são diferenciados por companhia aérea. Mais recentemente, Liu e Link (1999) indicam a presença de retornos crescentes do tamanho da rede de rotas aéreas, enquanto Creel e Farell (2001) apontam para a presença de economias de escala para baixos níveis de output e a inexistência em altos níveis de output. Ampliando o limite geográfico da análise e utilizando modelos DEA para determinar a eficiência de escala das companhias, Nolan, Ritchie e Rowcroft (2014) apontam para a heterogeneidade do indicador no grupo de empresas analisadas, tendo a maior parte delas apresentado retornos decrescentes em ao menos um dos anos da análise (1998/2010). Já no Brasil, os trabalhos de Silva (2001) e Guterres e Corrêa (2007) apontam para a existência de retornos constantes de escala no setor de transporte aéreo de passageiros.

Nota-se, dessa forma, que não há um consenso sobre qual seria o retorno de escala característico do setor aéreo. Mudanças nos marcos regulatórios, o período escolhido para calcular o retorno de escala e até mesmo eventos exógenos parecem influir diretamente na determinação do indicador. Especificamente no caso do Brasil, apesar de eles apontarem na mesma direção, as poucas e desatualizadas análises existentes não permitem responder com fidedignidade a essa pergunta.

Tendo em vista essa elevada "dispersão" das informações, com baixa uniformidade das conclusões a respeito da natureza dos retornos de escala do setor, optou-se, neste artigo, por aplicar os modelos DEA com quatro diferentes retornos de escala: retornos constantes (CRS), retornos variáveis (VRS), retornos crescentes (IRS) e retornos decrescentes (DRS).

\subsection{A TÉCNICA DO BOOTSTRAP NA DEA}

Há uma clara vantagem, no presente caso, de aplicabilidade da DEA com relação aos modelos paramétricos, como as fronteiras estocásticas (Stochastic Frontier Analysis SFA) e os modelos de regressão (Ordinary Least Squares - OLS; Corrected Ordinary Least Squares - COLS): a DEA permite a estimativa de uma fronteira determinística, sendo desnecessário conhecimento prévio sobre a função de produção e/ou as complexidades do mercado estudado, além de não incorrer no problema de omissão de 
variáveis, que é típico de modelos econométricos (CLEMENTE, GOMES e LÍRIO, 2015). Apesar disso, os modelos DEA têm a limitação de não permitir inferência estatística, minimizando o potencial de seus resultados.

Em termos práticos, a principal crítica à DEA é direcionada ao fato de que seus modelos assumem implicitamente que a distância entre as observações das DMU e a fronteira tecnológica reflete exclusivamente ineficiência. Ocorre que essa distância pode representar, além da ineficiência, um ruído (erro aleatório). Isto é, os dados de input e output utilizados no modelo podem estar sujeitos a erros de medição ou ainda a impactos de eventos não esperados.

A técnica do bootstrap, que começou a ser aplicada em modelos DEA a partir da década de 1990 com Simar e Wilson (1998), surge como uma alternativa para tentar corrigir esse problema. Ela permite corrigir as eficiências da DEA de vieses e estimar intervalos de confiança para elas, reconhecendo que os dados estão sujeitos a eventos aleatórios.

De uma forma geral, o bootstrap é um modelo de reamostragem simulada para criar intervalo de confiança nos dados e permitir a realização de testes de significância na amostra. As observações são escolhidas de forma aleatória e as estimativas são recalculadas (EFRON, 1979). No caso específico da DEA, pode-se entender como:

O PGD [processo de geração de dados] segue o princípio de que, restringindo às relações entre inputs e outputs, os elementos estocásticos no processo produtivo são englobados totalmente pelas medidas aleatórias de eficiência dos inputs. A ideia principal da simulação de bootstrap consiste na imitação do PGD. O procedimento para o algoritmo em cada reamostra, limitado pelas proporções entre inputs e outputs observadas, é construído segundo duas fases. Na primeira fase a fronteira de inputs é estimada e os pseudo-inputs do bootstrap são criados através da aplicação do PGD na fronteira estimada de inputs e das pseudo-eficiências, desenvolvido a partir de alguma estimativa da distribuição [original desconhecida] [...] Na segunda fase a estimativa da eficiência de bootstrap é obtida por intermédio da contabilização da distância do input original em relação à estimativa do bootstrap da fronteira. (MARQUES e SILVA, 2006, p. 100)

O uso do bootstrap neste artigo foi útil para gerar novos escores de eficiência, além daqueles gerados pelos modelos DEA regulares. Assim, para cada um dos quatro modelos utilizados (CRS, VRS, IRS e DRS), foram calculados quatro escores de eficiência: um regular, gerado antes do uso bootstrap; e três reestimados, gerados após o uso bootstrap. 
Esses três últimos resultados são: eficiência livre de viés e os limites (superior e inferior) do intervalo de confiança - a um nível de $95 \%$ - da eficiência livre de viés. ${ }^{5}$

O uso dos limites do intervalo de confiança, nesse caso, justifica-se como forma de apresentar a pior (limite superior) e a melhor (limite inferior) hipótese de ganho de eficiência decorrente da fusão. Contudo, a ênfase da análise recairá sobre o limite superior desse intervalo de confiança, que mostra o pior resultado possível economicamente. Entendemos que uma autoridade integrante de um sistema de defesa da concorrência e competente para avaliar atos de concentração - como o CADE - deva agir da forma mais conservadora possível, não admitindo que uma fusão, ainda que na pior das hipóteses (limite superior), traga maus resultados para o mercado. Essa precaução não seria possível em modelos básicos de DEA, que não originam intervalos de confiança.

Cabe ressaltar que a incorporação do bootstrap, no presente texto, serve muito mais ao propósito de aumentar a confiabilidade nos resultados dos modelos de DEA básicos, e menos, ao uso dos intervalos de confiança gerados pelo bootstrap em eventuais inferências estatísticas. Ademais, a tentativa de utilização de todas as propriedades do modelo DEA bootstrap no presente estudo é naturalmente restrita neste texto pela seguinte razão: os modelos atualmente existentes de decomposição dos efeitos totais da fusão em efeitos de aprendizado, harmonia e escala não permitem a geração de intervalos de confiança e nem incorporam diretamente o bootstrap. Resumindo: o bootstrap aprimora o modelo inicial da DEA, que calcula as eficiências, mas não pode gerar intervalos de confiança para cada componente (aprendizado, harmonia e escala) obtido na decomposição posterior dos efeitos da fusão.

No que se refere aos resultados que obtivemos, a adoção do bootstrap na DEA permite reduzir as incertezas quanto à precisão das estimativas de eficiência, ao calcular intervalos de confiança. Além disso, os estimadores básicos (originais) da DEA são enviesados para cima (otimistas), pois a fronteira estimada é, por construção, coincidente com a fronteira real ou está abaixo dessa fronteira real, que não pode ser observada. O viés ocorre porque não há como garantir que uma dada observação dos dados de uma DMU seja resultado da melhor realização possível da produção da referida DMU. As distâncias estimadas das DMU para a fronteira calculada no bootstrap são maiores, ou iguais, do que as distâncias estimadas das DMU para a fronteira calculada nos modelos básicos. Dito de outro modo, como a eficiência calculada no bootstrap

\footnotetext{
A versão original submetida à revista não contemplava o limite inferior do intervalo de confiança, dando a impressão de que todas as possibilidades testadas resultavam em perdas ou ganhos muito baixos de eficiência. Contudo, devido a uma crítica de um parecerista anônimo, que demandou maiores clarificações acerca do bootstrap, optamos por incluir o limite inferior no script do modelo e apresentar seus resultados.
} 
não é mais enviesada, os resultados dos escores de eficiência assim corrigidos são menores, ou iguais, aos resultados obtidos nos modelos tradicionais. Em resumo, os resultados que obtivemos com o bootstrap aplicado na DEA avaliam as empresas aéreas de modo mais severo do que ocorreria nos modelos determinísticos básicos de DEA.

Somando todas as eficiências obtidas neste artigo, chegamos a um total de 16 resultados diferentes (quatro resultados de eficiências para cada um dos quatro modelos de DEA utilizados).

\subsection{MODELO DE DEA PARA ANÁLISE DE FUSÕES}

Nesta seção apresentamos uma das principais inovações do presente texto: a avaliação, no estado da arte, dos efeitos econômicos de fusões das empresas sobre a eficiência setorial da aviação brasileira.

Uma vez que há o explícito objetivo de os modelos DEA apontarem o nível de eficiência das DMU que se encontram em análise, podemos fazer a análise de potenciais ganhos de eficiência decorrentes de atos de concentração. Com efeito, há alguma literatura que utiliza (e recomenda) tal técnica na análise de fusões. Jenking (2012), por exemplo, aponta como vantagens práticas da DEA na análise de fusões: não requer que sejam dados preços de inputs e outputs, o que pode ser uma informação difícil de conseguir em algumas indústrias, e pode flexibilizar as hipóteses tradicionais da teoria da produção (ex.: o objetivo de uma unidade produtiva pode não ser necessariamente maximização de lucros ou minimização de custos). Esses pontos se mostram altamente interessantes, do ponto de vista prático, para os órgãos de regulação e defesa da concorrência. Como há uma relativa facilidade para obter as informações necessárias em um modelo DEA e este pode ser executado muito rapidamente, haveria um ganho de agilidade nas análises e pareceres desses órgãos - fato muito relevante, tendo em vista a necessidade, muitas vezes, de decisões rápidas, sob pena de prejudicar a concorrência em determinado mercado. Além disso, deve-se levar em conta o ganho qualitativo da análise, uma vez que os modelos poderiam complementar a análise de mercado tradicional e os modelos econométricos, os quais são metodologias mais usuais nesse caso.

Outros estudos que relacionam o instrumental da DEA com as fusões podem ser citados: Kwoka e Pollitt (2010) avaliam fusões entre distribuidoras de energia nos EUA; e Kaur e Kaur (2010) tratam do caso de bancos comerciais indianos.

No Brasil não há trabalhos utilizando DEA para análise de fusões no setor da aviação. Existem alguns trabalhos que utilizaram a DEA para analisar o mercado de aviação (MELLO et al., 2003; ARAUJO JUNIOR et al., 2007; SAMPAIO e MELO, 2008; CORREIA, MELLO e MEZA, 2011), porém nenhum deles tratando de fusões especificamente.

Neste artigo foi utilizado o modelo de análise de fusão proposto por Bogetoft e Otto (2011). A escolha desse modelo foi baseada no fato de que o ganho de eficiência 
poderia ser decomposto em três efeitos distintos (aprendizado, harmonia e escala), contribuindo assim para o refinamento da análise dos resultados.

Ganho total de uma fusão: a partir de um modelo input orientado, o total dos ganhos potenciais de uma eventual fusão de $\mathrm{H}$ firmas pode ser mensurado por:

$$
E^{H}=\min \left\{E \in \mathbb{R}_{+} \mid\left(E \sum_{k \in H} x^{k}, \sum_{k \in H} y^{k}\right) \in T\right\}
$$

Acima, $E^{H}$ é a redução proporcional máxima nos inputs agregados das firmas fusionadas que permite gerar o output agregado das firmas fusionadas. Resultados abaixo da unidade $(1,0)$ indicam ganhos de eficiência com a fusão, e resultados acima da unidade $(1,0)$ indicam perdas de eficiência com a fusão.

Além do resultado agregado, essa metodologia permite decompor os ganhos (ou perdas) em três efeitos já aludidos: aprendizado; harmonia e escala. A formalização dos três será apresentada a seguir.

Efeito de aprendizado: esse efeito diz respeito à habilidade de a nova firma se ajustar às melhores práticas de mercado. Para se obter esse efeito é preciso, antes, calcular o ganho total de eficiência ajustado, que nada mais é do que o ganho total apresentado anteriormente calculado com a assunção de que as firmas fusionadas seriam eficientes (isto é, assume-se que elas estariam sobre a fronteira tecnológica):

$$
E^{* H}=\min \left\{E \in \mathbb{R}_{+} \mid\left(E \sum_{k \in H} E^{k} x^{k}, \sum_{k \in H} y^{k}\right) \in T\right\}
$$

A partir desse resultado é possível obter o efeito de aprendizado, relacionando-o com o ganho total:

$$
L E^{H}=\frac{E^{H}}{E^{* H}}
$$

O resultado do efeito de aprendizado varia de zero $(0,0)$ a um $(1,0)$, sendo maior o ganho quanto menor o resultado (se o indicador for igual à unidade $(1,0)$, não há ganho de aprendizado).

Efeito de harmonia: esse efeito está relacionado com a melhoria do mix de recursos utilizados e do mix de produtos oferecidos. Sua formalização examina quanto se pode reduzir do input médio utilizado pelas firmas fusionadas para produzir um output médio dado:

$$
H A^{H}=\min \left\{H A \in \mathbb{R}_{+} \mid\left(H A \frac{1}{H} \sum_{k \in H} E^{k} x^{k}, \frac{1}{H} \sum_{k \in H} y^{k}\right) \in T\right\}
$$


Resultados abaixo da unidade $(1,0)$ no efeito de harmonia indicam ganhos na harmonização de input-output, enquanto resultados acima da unidade $(1,0)$ indicam um aumento dos custos decorrentes dessa combinação de input-output.

Efeito de escala: está relacionado ao tamanho da operação após a fusão. Seu indicador mostra o quanto pode ser economizado com uma operação em maior escala:

$$
S I^{H}=\min \left\{S I \in \mathbb{R}_{+} \mid\left(S I \times H A^{H} \sum_{k \in H} E^{k} x^{k}, \sum_{k \in H} y^{k}\right) \in T\right\}
$$

Mais uma vez, resultados abaixo da unidade $(1,0)$ indicam ganhos e acima da unidade $(1,0)$ indicam perdas. Os três efeitos apresentados, quando multiplicados, devem resultar no efeito total (ganho de eficiência total): $E^{H}=L E^{H} \times H A^{H} \times S I^{H}$.

\section{METODOLOGIA}

Uma vez definido o instrumental a ser utilizado no estudo (DEA), foi necessário buscar os dados necessários para obter resultados analisáveis. Como os modelos DEA exigem o fornecimento de dados de input e de output, foi preciso buscar variáveis do setor de aviação civil comercial que servissem de proxy para esses elementos.

Outro ponto importante diz respeito ao número de DMU utilizadas na amostra. Como a fusão entre Azul e Trip ocorreu em 2012, procurou-se trabalhar com dados de 2012. Porém, nesse ano, só foram obtidas informações suficientes de sete companhias aéreas (sete DMU). Com esse número de DMU só seria possível executar um modelo DEA com um input e um output. ${ }^{6}$ Dessa forma, optou-se por buscar informações de anos anteriores (2010 e 2011), tratando cada companhia em cada ano como uma DMU diferente. Por exemplo: a empresa Azul aparece três vezes na amostra de DMU, como Azul-2010, Azul-2011 e Azul-2012. Dessa forma, foi possível aumentar o número de DMU para trinta e três (33). ${ }^{7}$

Infelizmente o número de informações disponíveis para o setor não é plenamente satisfatório, ficando um pouco limitada as escolhas de inputs e outputs. Ainda assim,

6 A experiência prática com modelos DEA mostra que o número de DMU da amostra deve ser pelo menos três vezes superior ao somatório de inputs e outputs.

7 Relação de DMU: Abaeté-2010, Avianca-2010, Azul-2010, Cruiser-2010, Gol-2010, Meta-2010, Nht2010, Noar-2010, Pantanal-2010, Passaredo-2010, Puma Air-2010, Rico-2010, Sete-2010, Sol-2010, Tam-2010, Team-2010, Total-2010, Trip-2010, Webjet-2010, Avianca-2011, Azul-2011, Gol-2011, Passaredo-2011, Tam-2011, Trip-2011, Webjet-2011, Avianca-2012, Azul-2012, Gol-2012, Passaredo-2012, Tam-2012, Trip-2012, Webjet-2012. 
procurou-se atender aos axiomas de coesão (escolha coerente de inputs e outputs), exaustão (descrever o problema levando em conta todos os aspectos relevantes) e não redundância (variáveis distintas que avaliam a mesma característica) (MELLO et al., 2001). A partir do Anuário do Transporte Aéreo (ANAC) e dos Dados Estatísticos do Transporte Aéreo do Brasil (ANAC) foi possível selecionar as seguintes variáveis (disponíveis para as $33 \mathrm{DMU})$ :

- número de funcionários;

- número de aeronaves;

- número de passageiros pagos transportados;

- $\operatorname{ASK}$ (Assentos-Quilômetros Oferecidos); ${ }^{8}$ e

- número de aeroportos atendidos. ${ }^{9}$

A Tabela 1 apresenta algumas estatísticas descritivas acerca dessas cinco variáveis escolhidas para o modelo DEA.

Tabela 1 - Estatísticas descritivas dos inputs e outputs selecionados

\begin{tabular}{|c|c|c|c|c|c|}
\hline \multirow[b]{2}{*}{ Indicador } & \multicolumn{2}{|c|}{ Input } & \multicolumn{3}{|c|}{ Output } \\
\hline & $\begin{array}{l}\text { Número de } \\
\text { funcionários }\end{array}$ & $\begin{array}{l}\text { Número de } \\
\text { aeronaves }\end{array}$ & $\begin{array}{c}\text { Passageiros } \\
\text { pagos } \\
\text { transportados }\end{array}$ & ASK & $\begin{array}{c}\text { Número de } \\
\text { aeroportos } \\
\text { atendidos }\end{array}$ \\
\hline Média & 5.209 & 42 & 7.280 .403 & 10.226 .857 & 32 \\
\hline Mediana & 1.683 & 23 & 2.719 .017 & 2.485 .116 & 27 \\
\hline Mínimo & 2 & 1 & 856 & 767 & 4 \\
\hline Máximo & 28.808 & 158 & 31.176 .531 & 48.742 .818 & 61 \\
\hline $\mathrm{HHI}^{*}$ & 1.098 & 723 & 986 & 1.102 & 399 \\
\hline
\end{tabular}

Nota: (*) Índice Herfindahl-Hirschman.

Fonte: Elaboração própria com base em dados da ANAC.

8 De acordo com a ANAC, o conceito de ASK refere-se ao volume de Assentos Quilometros Oferecidos, ou seja, a soma do produto entre o número de assentos oferecido e a distância das etapas. Há ainda um conceito semelhante, denominado RPK, o qual se refere ao volume de Passageiros Quilômetros Transportados, ou seja, a soma do produto entre o número de passageiros pagos e a distâncias das etapas.

9 Uma vez que a proposta do artigo é avaliar uma fusão, a partir de um modelo de fusão na DEA, foi necessário realizar um ajuste pontual no número de aeroportos atendidos das empresas participantes da fusão. Tendo em mente que o modelo de fusão realiza uma soma de inputs e outputs, a simples soma do número de aeroportos atendidos pelas empresas poderia proporcionar uma dupla contagem no resultado final do output da DMU resultante da fusão, caso as DMU pré-fusão atendessem a aeroportos específicos de forma simultânea. Assim, foi preciso verificar a quais aeroportos a Azul e a Trip atendiam em 2010, 2011 e 2012, identificar quais deles eram atendidos pelas duas companhias e, por fim, excluir esses aeroportos da contagem de uma das duas companhias. Aqui optou-se por reduzir o número da companhia que atendia ao maior número de aeroportos nos respectivos anos, no caso, a Trip. Assim, o número de aeroportos atendidos pela Trip diminuiu de: 96 para 60, em 2010; 96 para 58 em 2011; e 102 para 49 em 2012. 
O processo de escolha das variáveis foi efetivado por meio de análise de correlação linear entre as variáveis de input e output. As correlações entre as variáveis de input e output se mostraram muito elevadas (acima de 0,9 em todos as simulações), o que pode indicar uma relação de nexo causal entre elas. Ademais, o baixo número de variáveis vis-à-vis o número de DMU contribui para o aumento da discriminação dos modelos DEA em questão.

Acerca da determinação das variáveis como inputs ou outputs (princípio da coesão), procurou-se separar aquelas que têm relação próxima com o conceito de custo, daquelas que têm relação próxima com a ideia de oferta do serviço. Dessa forma, as duas primeiras variáveis foram classificadas como inputs e as três seguintes como outputs.

Dessa forma, a partir das cinco variáveis selecionadas e da classificação delas como inputs ou outputs foram propostas três simulações (simulações). No primeiro teste, os modelos DEA foram calculados com dois inputs - número de funcionários e número de aeronaves - e três outputs - número de passageiros pagos transportados, ASK e número de aeroportos atendidos. No segundo teste, os modelos DEA também foram calculados com dois inputs - número de funcionários e número de aeronaves -, mas com apenas dois outputs - número de passageiros pagos transportados e número de aeroportos atendidos. Por fim, no terceiro teste, os modelos DEA foram calculados com dois inputs - número de funcionários e número de aeronaves - e dois outputs ASK e número de aeroportos atendidos.

Foram utilizados os quatro modelos DEA apresentados anteriormente (CRS, VRS, IRS e DRS) com orientação input (priorizando a minimização de custos), os quais geraram quatro resultados de eficiência cada (regular, sem viés, limite superior do intervalo de confiança e limite inferior do intervalo de confiança).

O software R foi utilizado para os cálculos dos modelos e nas simulações de fusões. Dois pacotes do $\mathrm{R}$ foram usados simultaneamente: benchmarking (BOGETOFT e OTTO, 2011) e boot, que já vêm instalados no software R.

Por fim, vale destacar que a simulação de fusão foi realizada entre todas as DMU da empresa Azul (2010, 2011 e 2012) e da empresa Trip (2010, 2011 e 2012), totalizando nove fusões possíveis. ${ }^{10}$ Notavelmente, a fusão entre Azul-2012 e Trip-2012 teve destaque na análise dos resultados por se tratar da fusão "original" - isto é, a fusão que efetivamente ocorreu.

10 As possibilidades são: Azul-2010+Trip-2010; Azul-2010+Trip-2011; Azul-2010+Trip-2012; Azul-2011+Trip-2010; Azul-2011+Trip-2011; Azul-2011+Trip-2012; Azul-2012+Trip-2010; Azul-2012+Trip-2011; e Azul-2012+Trip-2012. 


\section{ANÁLISE DOS RESULTADOS}

Nesta seção os resultados serão dispostos conforme o tipo de simulação (teste) apresentado na seção metodológica. Por fim, algumas conclusões gerais serão destacadas.

\subsection{RESULTADOS DO TESTE 1}

Relembrando, o teste 1 contou com dois inputs ( $\mathrm{n}^{\circ}$ de funcionários e $\mathrm{n}^{\circ}$ de aeronaves) e três outputs ( $\mathrm{n}^{\circ}$ de passageiros pagos transportados, ASK e $\mathrm{n}^{\circ}$ de aeroportos atendidos) e a simulação de fusão foi feita para nove fusões possíveis (mas nem todas efetivadas) entre as empresas Trip e Azul, de onde foram extraídos os resultados médios apresentados na Tabela 2.

Tabela 2 - Ganhos potenciais médios decorrentes das fusões no teste 1

\begin{tabular}{|c|c|c|c|c|c|}
\hline Modelo & Eficiência & $\begin{array}{l}\text { Eficiência } \\
\text { ajustada }\end{array}$ & Aprendizado & Harmonia & Escala \\
\hline dea-crs & 0,563 & 0,980 & 0,574 & 0,980 & 1,000 \\
\hline dea-crs-biascorr & 0,928 & 0,985 & 0,942 & 0,985 & 1,000 \\
\hline dea-crs-biascorr-max & 0,980 & 0,986 & 0,993 & 0,986 & 1,000 \\
\hline dea-crs-biascorr-min & 0,790 & 1,000 & 0,791 & 1,000 & 1,000 \\
\hline dea-vrs & Inf & Inf & NA & 0,900 & Inf \\
\hline dea-vrs-biascorr & $\operatorname{Inf}$ & Inf & NA & 0,901 & Inf \\
\hline dea-vrs-biascorr-max & $\operatorname{Inf}$ & Inf & NA & 0,900 & Inf \\
\hline dea-vrs-biascorr-min & Inf & Inf & NA & 0,900 & Inf \\
\hline dea-irs & 0,563 & 0,980 & 0,574 & 0,980 & 1,000 \\
\hline dea-irs-biascorr & 0,929 & 0,984 & 0,944 & 0,984 & 1,000 \\
\hline dea-irs-biascorr-max & 0,974 & 0,985 & 0,990 & 0,985 & 1,000 \\
\hline dea-irs-biascorr-min & 0,794 & 0,999 & 0,796 & 0,999 & 1,000 \\
\hline dea-drs & $\operatorname{Inf}$ & Inf & NA & 0,900 & Inf \\
\hline dea-drs-biascorr & Inf & Inf & NA & 0,900 & Inf \\
\hline dea-drs-biascorr-max & Inf & Inf & NA & 0,899 & Inf \\
\hline dea-drs-biascorr-min & $\operatorname{Inf}$ & Inf & NA & 0,895 & Inf \\
\hline Média sem correção & 0,563 & 0,980 & 0,574 & 0,940 & 1,000 \\
\hline Média "Ótima"* & 0,928 & 0,984 & 0,943 & 0,942 & 1,000 \\
\hline $\begin{array}{l}\text { Média Limite Superior } \\
\text { do IC } \text { IC* }^{* *}\end{array}$ & 0,977 & 0,986 & 0,991 & 0,942 & 1,000 \\
\hline
\end{tabular}

Notas: Inf = infinito; NA = não disponível. $\left(^{\star}\right)$ Média dos modelos corrigidos pelo bootstrap. $\left(^{* *}\right)$ Média do limite superior dos intervalos de confiança (95\%) dos modelos corrigidos pelo bootstrap. Hipótese de pior dos cenários.

Fonte: Elaboração própria com base em dados da ANAC. 
Como é possível notar, apenas dois (CRS e IRS) dos quatro modelos utilizados (CRS, VRS, IRS e DRS) apresentaram resultados mensuráveis. Os outros dois modelos (VRS e DRS) apresentaram, invariavelmente (inclusive nos testes 2 e 3), como resultado, "mais infinito" - o que, a rigor, pode ser interpretado como um indicativo de perda de eficiência decorrente das fusões simuladas. Essa perda, contudo, não é mensurável.

Vale a pena, neste momento, fazer uma rápida digressão acerca da obtenção desse resultado. Buscando a literatura mais tradicional sobre DEA, como Charnes, Cooper e Rhodes (1978) e Banker, Charnes e Cooper (1984), é possível inferir que o modelo BCC (VRS) foi desenvolvido com o intuito de tornar mais "realista" a aplicação da DEA, ao não assumir, por exemplo, que as DMU operem com tamanho ótimo em um mercado de competição perfeita, como é o caso do modelo CCR (CRS). Não é por acaso que o modelo VRS, ao incorporar todas as possibilidades de retornos de escala (CRS, IRS e DRA) simultaneamente, é mais "benevolente" com as DMU, proporcionando, para estas, na média, escores de eficiência mais elevados do que no modelo CRS. Assim, uma vez que se utiliza um modelo VRS para avaliar uma fusão, há uma clara tendência de esse modelo apontar menor ganho de eficiência da fusão do que o modelo CRS. Em outras palavras, como as empresas participantes da fusão já se encontram, individualmente, em um nível de eficiência mais elevado ( $v i s-\grave{a}$ - $v i$ s caso do modelo CRS), haveria, portanto, uma justificativa menor para proceder com a fusão. Partindo desse princípio lógico, baseado na teoria sobre DEA, é mais do que razoável afirmar que os resultados dos modelos VRS e DRS, caso fossem mensuráveis, apontariam para uma perda de eficiência decorrente das fusões simuladas - o que, por sua vez, tornaria a média geral dos quatro modelos bem mais próxima da unidade ou, eventualmente, acima da unidade.

Fazendo a média dos escores de eficiência obtidos e mensuráveis, chega-se a um resultado de 0,928 nos dados corrigidos pelo bootstrap, o que indica um ganho de eficiência de aproximadamente 7,2\%, na média das nove fusões possíveis. Esse resultado pode ser atribuído, principalmente, ao ganho de aprendizado e de harmonização de inputs e outputs. O efeito de escala, por outro lado, é o único componente que não contribui para a melhora do resultado global. Como os resultados pós-bootstrap tendem a ser estatisticamente mais confiáveis, este último indicador de ganho de eficiência pode estar mais próximo da realidade do que o resultado regular da DEA.

Se tomarmos apenas a média dos escores do limite superior do intervalo de confiança (descartando os limites inferiores dos modelos mensuráveis, i.e., CRS e IRS), esse ganho de eficiência é sensivelmente reduzido, chegando a menos de 3\% (indicador de 0,977$)$. Esse último resultado é interessante por mostrar qual seria o pior cenário em termos de ganho de eficiência da média das fusões no teste 1.

A Tabela 3 apresenta os mesmos indicadores, porém exclusivos para a fusão "original" (Azul-2012 e Trip-2012). 
Tabela 3 - Ganhos potenciais médios decorrentes da fusão original no teste 1

\begin{tabular}{|c|c|c|c|c|c|}
\hline Modelo & Eficiência & $\begin{array}{l}\text { Eficiência } \\
\text { ajustada }\end{array}$ & Aprendizado & Harmonia & Escala \\
\hline dea-crs & 0,617 & 0,974 & 0,633 & 0,974 & 1,000 \\
\hline dea-crs-biascorr & 0,929 & 0,983 & 0,945 & 0,983 & 1,000 \\
\hline dea-crs-biascorr-max & 0,980 & 0,983 & 0,997 & 0,983 & 1,000 \\
\hline dea-crs-biascorr-min & 0,801 & 1,000 & 0,801 & 1,000 & 1,000 \\
\hline dea-vrs & Inf & Inf & NA & 0,900 & Inf \\
\hline dea-vrs-biascorr & Inf & Inf & NA & 0,901 & Inf \\
\hline dea-vrs-biascorr-max & Inf & Inf & NA & 0,900 & Inf \\
\hline dea-vrs-biascorr-min & Inf & Inf & NA & 0,900 & Inf \\
\hline dea-irs & 0,617 & 0,974 & 0,633 & 0,974 & 1,000 \\
\hline dea-irs-biascorr & 0,930 & 0,982 & 0,947 & 0,982 & 1,000 \\
\hline dea-irs-biascorr-max & 0,976 & 0,981 & 0,995 & 0,981 & 1,000 \\
\hline dea-irs-biascorr-min & 0,807 & 1,000 & 0,807 & 1,000 & 1,000 \\
\hline dea-drs & Inf & Inf & NA & 1,000 & Inf \\
\hline dea-drs-biascorr & Inf & Inf & NA & 1,000 & Inf \\
\hline dea-drs-biascorr-max & Inf & Inf & NA & 1,000 & Inf \\
\hline dea-drs-biascorr-min & Inf & Inf & NA & 1,000 & Inf \\
\hline Média sem correção & 0,617 & 0,974 & 0,633 & 0,987 & 1,000 \\
\hline Média "Ótima"* & 0,929 & 0,983 & 0,946 & 0,991 & 1,000 \\
\hline $\begin{array}{l}\text { Média Limite } \\
\text { Superior do IC }\end{array}$ & 0,978 & 0,982 & 0,996 & 0,991 & 1,000 \\
\hline
\end{tabular}

Nota: Inf = infinito; NA = não disponível. (*) Média dos modelos corrigidos pelo bootstrap. ${ }^{* *}$ ) Média do limite superior dos intervalos de confiança ( $95 \%$ ) dos modelos corrigidos pelo bootstrap. Hipótese de pior dos cenários.

Fonte: Elaboração própria com base em dados da ANAC.

Nesse caso, os resultados se mostraram bastante parecidos com aqueles obtidos para a média das nove fusões simuladas, com uma pequena redução do ganho total de eficiência na média "ótima” (indicador de 0,929, indicando um ganho de aproximadamente 7\%) e no limite superior do intervalo de confiança (aproximadamente 2\%). Lembrando que esses resultados se referem apenas aos modelos CRS e IRS, mais uma vez é possível notar que o efeito de escala não tem influência nos eventuais ganhos da fusão, sendo qualquer ganho decorrente dos efeitos de aprendizado e de harmonia.

\subsection{RESULTADOS DO TESTE 2}

Relembrando, o teste 2 contou com dois inputs ( $\mathrm{n}^{\circ}$ de funcionários e $\mathrm{n}^{\circ}$ de aeronaves) e dois outputs ( $\mathrm{n}^{\circ}$ de passageiros pagos transportados e $\mathrm{n}^{\circ}$ de aeroportos atendidos) e 
a simulação de fusão foi feita para nove fusões possíveis, de onde foram extraídos os resultados médios apresentados na Tabela 4 .

Tabela 4 - Ganhos potenciais médios decorrentes das fusões no teste 2

\begin{tabular}{|c|c|c|c|c|c|}
\hline Modelo & Eficiência & $\begin{array}{l}\text { Eficiência } \\
\text { ajustada }\end{array}$ & Aprendizado & Harmonia & Escala \\
\hline dea-crs & 0,560 & 0,982 & 0,571 & 0,982 & 1,000 \\
\hline dea-crs-biascorr & 0,934 & 0,985 & 0,949 & 0,985 & 1,000 \\
\hline dea-crs-biascorr-max & 0,982 & 0,985 & 0,997 & 0,985 & 1,000 \\
\hline dea-crs-biascorr-min & 0,850 & 1,000 & 0,850 & 1,000 & 1,000 \\
\hline dea-vrs & Inf & Inf & NA & 0,900 & Inf \\
\hline dea-vrs-biascorr & Inf & Inf & NA & 0,901 & Inf \\
\hline dea-vrs-biascorr-max & Inf & Inf & NA & 0,900 & $\operatorname{Inf}$ \\
\hline dea-vrs-biascorr-min & Inf & $\operatorname{Inf}$ & NA & 0,900 & $\operatorname{Inf}$ \\
\hline dea-irs & 0,560 & 0,980 & 0,571 & 0,980 & 1,000 \\
\hline dea-irs-biascorr & 0,934 & 0,983 & 0,950 & 0,983 & 1,000 \\
\hline dea-irs-biascorr-max & 0,978 & 0,983 & 0,996 & 0,983 & 1,000 \\
\hline dea-irs-biascorr-min & 0,857 & 0,999 & 0,858 & 0,999 & 1,000 \\
\hline dea-drs & Inf & Inf & NA & 0,901 & $\operatorname{Inf}$ \\
\hline dea-drs-biascorr & Inf & Inf & NA & 0,901 & Inf \\
\hline dea-drs-biascorr-max & $\operatorname{Inf}$ & Inf & NA & 0,896 & $\operatorname{Inf}$ \\
\hline dea-drs-biascorr-min & Inf & Inf & NA & 0,898 & Inf \\
\hline Média sem correção & 0,560 & 0,981 & 0,571 & 0,941 & 1,000 \\
\hline Média "Ótima”* & 0,934 & 0,984 & 0,949 & 0,942 & 1,000 \\
\hline $\begin{array}{l}\text { Média Limite Superior } \\
\text { do } \mathrm{IC}^{\star *}\end{array}$ & 0,980 & 0,984 & 0,996 & 0,941 & 1,000 \\
\hline
\end{tabular}

Nota: Inf = infinito; NA = não disponível. ${ }^{*}$ ) Média dos modelos corrigidos pelo bootstrap. ${ }^{* *}$ ) Média do limite superior dos intervalos de confiança (95\%) dos modelos corrigidos pelo bootstrap. Hipótese de pior dos cenários.

Fonte: Elaboração própria com base em dados da ANAC.

Nesse teste, considerando apenas aqueles modelos com resultados mensuráveis (CRS e IRS), o ganho médio "ótimo" de eficiência de todas as nove fusões chega a quase $7 \%(0,934)$, que leva em conta os escores da DEA pós bootstrap. Porém, na média dos limites superiores do intervalo de confiança (pior hipótese possível), esse ganho cai para $2 \%(0,980)$. Em ambos os casos não houve ganho a partir do efeito de escala. Os efeitos de harmonia (principalmente) e de aprendizado são positivos para as fusões.

A Tabela 5 apresenta os mesmos indicadores, porém exclusivos para a fusão "original" que efetivamente ocorreu (Azul-2012 e Trip-2012). 
Tabela 5 - Ganhos potenciais médios decorrentes da fusão original no teste 2

\begin{tabular}{|c|c|c|c|c|c|}
\hline Modelo & Eficiência & $\begin{array}{c}\text { Eficiência } \\
\text { ajustada }\end{array}$ & Aprendizado & Harmonia & Escala \\
\hline dea-crs & 0,617 & 0,974 & 0,633 & 0,974 & 1,000 \\
\hline dea-crs-biascorr & 0,938 & 0,981 & 0,956 & 0,981 & 1,000 \\
\hline dea-crs-biascorr-max & 0,980 & 0,980 & 1,000 & 0,980 & 1,000 \\
\hline dea-crs-biascorr-min & 0,873 & 1,000 & 0,873 & 1,000 & 1,000 \\
\hline dea-vrs & Inf & Inf & NA & 0,900 & Inf \\
\hline dea-vrs-biascorr & Inf & Inf & NA & 0,901 & $\operatorname{Inf}$ \\
\hline dea-vrs-biascorr-max & Inf & Inf & NA & 0,900 & $\operatorname{Inf}$ \\
\hline dea-vrs-biascorr-min & Inf & Inf & NA & 0,900 & $\operatorname{Inf}$ \\
\hline dea-irs & 0,617 & 0,974 & 0,633 & 0,974 & 1,000 \\
\hline dea-irs-biascorr & 0,938 & 0,980 & 0,957 & 0,980 & 1,000 \\
\hline dea-irs-biascorr-max & 0,979 & 0,979 & 1,000 & 0,979 & 1,000 \\
\hline dea-irs-biascorr-min & 0,880 & 1,000 & 0,880 & 1,000 & 1,000 \\
\hline dea-drs & Inf & Inf & NA & 1,000 & Inf \\
\hline dea-drs-biascorr & Inf & Inf & NA & 1,000 & Inf \\
\hline dea-drs-biascorr-max & Inf & Inf & NA & 1,000 & Inf \\
\hline dea-drs-biascorr-min & Inf & Inf & NA & 1,000 & Inf \\
\hline Média sem correção & 0,617 & 0,974 & 0,633 & 0,987 & 1,000 \\
\hline Média "Ótima"* & 0,938 & 0,980 & 0,957 & 0,990 & 1,000 \\
\hline $\begin{array}{l}\text { Média Limite Superior } \\
\text { do IC }\end{array}$ & 0,979 & 0,979 & 1,000 & 0,990 & 1,000 \\
\hline
\end{tabular}

Nota: Inf = infinito; NA = não disponível. ( ${ }^{*}$ ) Média dos modelos corrigidos pelo bootstrap. ${ }^{* *}$ ) Média do limite superior dos intervalos de confiança (95\%) dos modelos corrigidos pelo bootstrap. Hipótese de pior dos cenários.

Fonte: Elaboração própria com base em dados da ANAC.

Reforçando que essa média não inclui os resultados dos modelos não mensuráveis (VRS e IRS), mais uma vez verifica-se uma pequena piora dos indicadores médios "otimizados" com relação à média das nove fusões: o ganho total de eficiência da referida fusão chegaria a $6,2 \%(0,938)$. Já na média do limite superior do intervalo de confiança haveria uma perda de eficiência da ordem de $2,1 \%(0,979)$. O efeito de aprendizado explica quase totalmente o ganho total com a fusão na média otimizada, haja vista que, nesse caso, o efeito de harmonia tem impacto marginal (cerca de $1 \%$ ) e o efeito de escala não apresenta qualquer influência no ganho decorrente da fusão. No caso da hipótese do pior cenário decorrente da fusão, haveria apenas um ganho marginal na harmonia de inputs e outputs. 


\subsection{RESULTADOS DO TESTE 3}

Relembrando, o teste 3 contou com dois inputs ( $\mathrm{n}^{\circ}$ de funcionários e $\mathrm{n}^{\circ}$ de aeronaves) e dois outputs (ASK e $\mathrm{n}^{\circ}$ de aeroportos atendidos) e a simulação de fusão foi feita para nove fusões possíveis, de onde foram extraídos os resultados médios dos modelos mensuráveis (CRS e IRS) apresentados na Tabela 6.

Tabela 6 - Ganhos potenciais médios decorrentes das fusões no teste 3

\begin{tabular}{|c|c|c|c|c|c|}
\hline Modelo & Eficiência & $\begin{array}{l}\text { Eficiência } \\
\text { ajustada }\end{array}$ & Aprendizado & Harmonia & Escala \\
\hline dea-crs & 0,527 & 0,998 & 0,528 & 0,998 & 1,000 \\
\hline dea-crs-biascorr & 0,918 & 0,999 & 0,919 & 0,999 & 1,000 \\
\hline dea-crs-biascorr-max & 0,986 & 0,999 & 0,987 & 0,999 & 1,000 \\
\hline dea-crs-biascorr-min & 0,734 & 1,000 & 0,734 & 1,000 & 1,000 \\
\hline dea-vrs & Inf & Inf & NA & 0,898 & Inf \\
\hline dea-vrs-biascorr & Inf & Inf & NA & 0,899 & Inf \\
\hline dea-vrs-biascorr-max & Inf & $\operatorname{Inf}$ & NA & 0,898 & Inf \\
\hline dea-vrs-biascorr-min & Inf & Inf & NA & 0,899 & Inf \\
\hline dea-irs & 0,527 & 0,998 & 0,528 & 0,998 & 1,000 \\
\hline dea-irs-biascorr & 0,924 & 0,999 & 0,925 & 0,999 & 1,000 \\
\hline dea-irs-biascorr-max & 0,984 & 1,000 & 0,985 & 1,000 & 1,000 \\
\hline dea-irs-biascorr-min & 0,748 & 1,000 & 0,748 & 1,000 & 1,000 \\
\hline dea-drs & Inf & Inf & NA & 0,898 & $\operatorname{Inf}$ \\
\hline dea-drs-biascorr & Inf & Inf & NA & 0,898 & Inf \\
\hline dea-drs-biascorr-max & Inf & Inf & NA & 0,897 & Inf \\
\hline dea-drs-biascorr-min & Inf & Inf & NA & 0,984 & Inf \\
\hline Média sem correção & 0,527 & 0,998 & 0,528 & 0,948 & 1,000 \\
\hline Média "Ótima”* & 0,921 & 0,999 & 0,922 & 0,949 & 1,000 \\
\hline $\begin{array}{l}\text { Média Limite } \\
\text { Superior do IC }{ }^{\star *}\end{array}$ & 0,985 & 0,999 & 0,986 & 0,949 & 1,000 \\
\hline
\end{tabular}

Nota: Inf = infinito; NA = não disponível. (*) Média dos modelos corrigidos pelo bootstrap. ${ }^{* *}$ ) Média do limite superior dos intervalos de confiança (95\%) dos modelos corrigidos pelo bootstrap. Hipótese de pior dos cenários.

Fonte: Elaboração própria com base em dados da ANAC.

O resultado desse teste indica um ganho médio "ótimo" de eficiência de pouco menos que $8 \%(0,921)$ na média das nove fusões, majoritariamente decorrente de efeitos de aprendizado. Já a média do limite superior do intervalo de confiança, por outro lado, apresentou ganhos de eficiência bem mais modestos, de 1,5\%, aproximadamente $(0,985)$. O efeito de escala, novamente, apresentou índice igual à unidade, indicando 
não haver ganhos relativos ao tamanho da nova firma resultante da operação. O efeito de harmonia, por sua vez, predominou com relação aos ganhos de aprendizado.

A Tabela 7 apresenta os mesmos indicadores, porém exclusivos para a fusão efetivamente ocorrida (Azul-2012 e Trip-2012).

Tabela 7 - Ganhos potenciais médios decorrentes das fusões no teste 3

\begin{tabular}{|c|c|c|c|c|c|}
\hline Modelo & Eficiência & $\begin{array}{c}\text { Eficiência } \\
\text { ajustada }\end{array}$ & Aprendizado & Harmonia & Escala \\
\hline dea-crs & 0,568 & 1,000 & 0,568 & 1,000 & 1,000 \\
\hline dea-crs-biascorr & 0,920 & 1,000 & 0,920 & 1,000 & 1,000 \\
\hline dea-crs-biascorr-max & 0,992 & 1,000 & 0,992 & 1,000 & 1,000 \\
\hline dea-crs-biascorr-min & 0,743 & 1,000 & 0,743 & 1,000 & 1,000 \\
\hline dea-vrs & Inf & Inf & NA & 0,980 & Inf \\
\hline dea-vrs-biascorr & Inf & Inf & NA & 0,981 & Inf \\
\hline dea-vrs-biascorr-max & Inf & Inf & NA & 0,980 & Inf \\
\hline dea-vrs-biascorr-min & Inf & Inf & NA & 0,980 & $\operatorname{Inf}$ \\
\hline dea-irs & 0,568 & 1,000 & 0,568 & 1,000 & 1,000 \\
\hline dea-irs-biascorr & 0,924 & 1,000 & 0,924 & 1,000 & 1,000 \\
\hline dea-irs-biascorr-max & 0,990 & 1,000 & 0,990 & 1,000 & 1,000 \\
\hline dea-irs-biascorr-min & 0,753 & 1,000 & 0,753 & 1,000 & 1,000 \\
\hline dea-drs & Inf & Inf & NA & 0,980 & Inf \\
\hline dea-drs-biascorr & Inf & Inf & NA & 0,981 & $\operatorname{Inf}$ \\
\hline dea-drs-biascorr-max & $\operatorname{Inf}$ & Inf & NA & 0,980 & $\operatorname{Inf}$ \\
\hline dea-drs-biascorr-min & Inf & Inf & NA & 0,984 & $\operatorname{Inf}$ \\
\hline Média sem correção & 0,568 & 1,000 & 0,568 & 0,990 & 1,000 \\
\hline Média "Ótima"* & 0,922 & 1,000 & 0,922 & 0,990 & 1,000 \\
\hline $\begin{array}{l}\text { Média Limite } \\
\text { Superior do IC }\end{array}$ & 0,991 & 1,000 & 0,991 & 0,990 & 1,000 \\
\hline
\end{tabular}

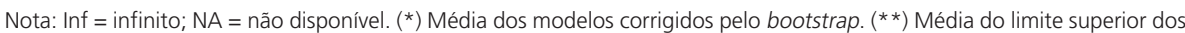
intervalos de confiança (95\%) dos modelos corrigidos pelo bootstrap. Hipótese de pior dos cenários.

Fonte: Elaboração própria com base em dados da ANAC.

Assim como no teste anterior, os resultados aqui mostram que a fusão entre Azul2012 e Trip-2012 obteria um ganho total de eficiência menor do que a média das nove fusões simuladas: de 7,8\% $(0,922)$ na média otimizada e uma ganho de eficiência de $0,9 \%(0,991)$ na média otimizada limítrofe (máximo) - o que demonstra praticamente a ausência de ganhos no pior dos cenários. Em ambos os casos os ganhos decorrem de efeitos de aprendizado. $\mathrm{O}$ efeito de escala não interfere no processo, e a harmonia proporciona ganhos marginais. 


\subsection{TENDÊNCIAS GERAIS DOS RESULTADOS}

Analisando as simulações de forma agregada, pode-se observar que o ganho médio de eficiência ${ }^{11}$ das nove fusões potenciais, a partir dos escores ajustados (pós-bootstrap), foi de 7,2\% e 1,9\%, quando considerados apenas os escores limítrofes (máximo) do intervalo de confiança da série ajustada (hipótese de pior cenário possível). Na análise da fusão original (Azul-2012 e Trip-2012), essas variações na eficiência se mostram ainda menores, com patamares de, respectivamente, 7,0\% e 1,7\%. Ou seja, utilizando apenas os dados livres de viés e restritos aos modelos CRS e IRS (mensuráveis), a fusão entre Azul e Trip geraria um ganho pequeno de eficiência. Tal ganho seria praticamente anulado caso considerássemos o caso extremo dado pelos resultados do limite superior do intervalo de confiança. Vale lembrar que uma autoridade antitruste conservadora deveria levar em conta, de forma enfática, essa possibilidade do pior cenário possível.

Apesar dos resultados apresentados até aqui já demonstrarem uma baixa aderência do argumento "eficiência" em favor da fusão, existem outros aspectos que precisam ser levados em conta e que corroboram com essa tese. Ao serem consideradas as possibilidades teóricas dos resultados dos modelos VRS e DRS - os quais indicam um resultado elevado, porém não mensurável -, compreende-se que não se pode afirmar que haveria ganho de eficiência, inclusive havendo a real possibilidade de indicação de perda de eficiência, na média. Então, sob esse critério estrito de eficiência econômica com solidez estatística e observando as indicações dos modelos VRS e DRS, a fusão não seria recomendada.

Observando os componentes da eficiência total é possível observar uma tendência bastante comportada, na qual os efeitos de aprendizado e de harmonia sempre contribuem - ainda que marginalmente em alguns casos - para a melhoria da eficiência, e os efeitos de escala são quase imperceptíveis. Esse resultado é especialmente interessante por revelar que eventuais ganhos dessa fusão não seriam decorrentes do maior tamanho da firma (escala), estando mais próximos de uma situação de ganhos sinérgicos (FARREL e SHAPIRO, 1990, 2001). Não podemos refutar a hipótese de que a empresa gerada pela fusão seria demasiadamente grande.

Outro ponto que chama a atenção é o fato de que os ganhos médios de eficiência das nove fusões são quase sempre superiores aos da fusão original. Essa evidência induziu a uma análise de cada fusão individualmente, que resultou no Gráfico 1.

11 Chegou-se ao ganho médio de eficiência a partir da média simples dos escores de eficiência obtidos em todos os modelos DEA nos três testes. No caso do ganho médio "ótimo", apenas os escores ajustados foram utilizados para calcular a média. 


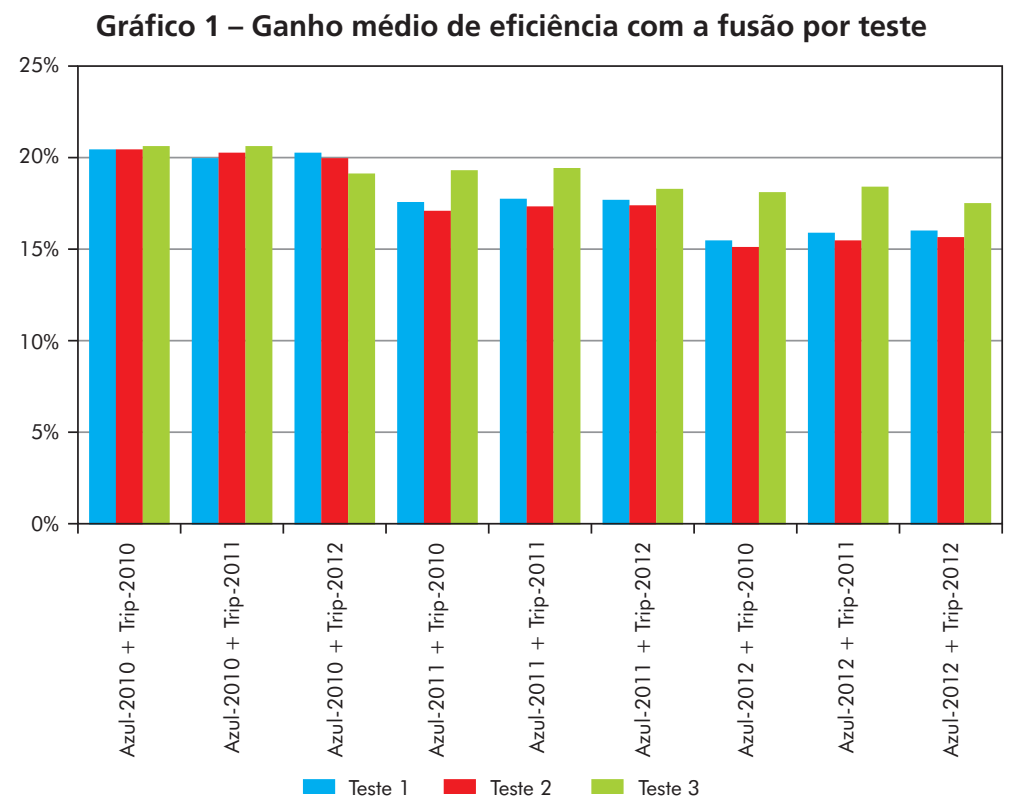

Fonte: Elaboração própria com base em dados da ANAC.

Como é possível observar, fica clara a tendência de diminuição dos ganhos de eficiência conforme se muda das DMU mais “antigas” (Azul-2010 e Trip-2010) para as DMU mais “novas” (Azul-2012 e Trip-2012). Tal resultado pode estar indicando que as DMU mais recentes apresentariam um nível inicial (pré-fusão) de eficiência superior às DMU antigas, estando sujeitas a obter menos ganho de eficiência pós-fusão. Explicando de outra forma, tanto a empresa Azul como a Trip aumentaram individualmente suas eficiências entre 2010 e 2012, ${ }^{12}$ diminuindo a importância da alegação de ganho de eficiência para a fusão. De acordo com Farrel e Shapiro (2001), uma fusão só deveria ser aprovada caso as firmas envolvidas no ato de concentração não tivessem capacidade para alcançar ganhos de eficiência individualmente - o que não parece ser o caso em questão.

12 Tal afirmação, além de ser sugestionada pela análise de ganhos de eficiência a partir das fusões, é corroborada pela avaliação individual de eficiência pré-fusão, que foram obtidas a partir dos modelos utilizados neste artigo. 


\section{CONSIDERAÇÕES FINAIS}

Este artigo procurou avaliar, a partir mensuração dos potenciais ganhos de eficiência, o acordo de fusão entre as companhias aéreas Azul e Trip ocorrido em 2012. O esforço revelou-se recompensado, visto que se fez uso de metodologia ainda não incorporada ao menu de ferramentas para análises de impactos de fusões por simulação - o que tem especial importância ex-ante, não obstante seja também útil para a análise ex-post facto - obtendo-se resultados que merecem atenção.

Para alcançar o objetivo de análise de ganhos de eficiência no presente caso, o instrumental da DEA foi utilizado conjuntamente com uma técnica de reamostragem de dados denominada bootstrap. A simples e usual alegação de ganhos de eficiência e maior pressão competitiva sobre as empresas líderes, em análises de fusões de empresas, como no caso em tela da Trip e Azul, podem não ser suficientes para suplantar as perdas com as poucas escolhas disponíveis para os consumidores, a maior facilidade para coordenação de preços entre as empresas (conluio) e o quase completo domínio de rotas regionais decorrentes da referida fusão.

A partir de dados disponíveis no site da ANAC foi possível executar os modelos DEA e simular algumas fusões entre as companhias Azul e Trip. Todas as simulações indicaram que, com dados corrigidos de viés (pós-bootstrap) dos modelos com resultado mensuráveis, os ganhos de eficiência das fusões seriam muito pequenos ou quase nulos. Inferiu-se ainda a real possibilidade de esse ganho ser ainda mais marginal ou até mesmo negativo caso os modelos VRS e DRS apresentassem resultados mensuráveis. Ademais, ficou comprovado que as empresas aumentaram individualmente sua eficiência entre 2010 e 2012, tornando menos interessante o argumento de ganho de eficiência decorrente do ato de concentração.

Além disso, a aprovação do ato de concentração pelo CADE é passível de críticas, na medida em que terá contribuído para concentrar ainda mais o mercado aéreo nacional. Tal movimento em favor do domínio de duas ou três empresas na maior parte das rotas também pode ser observado nos EUA nas últimas décadas. Naquele país, os efeitos da alta concentração são sentidos em termos de aumento de tarifas. De acordo com levantamento da Associated Press (AP) (CHICAGO TRIBUNE, 2015), as fusões no setor aéreo americano reduziram o número de grandes empresas de transporte aéreo de nove para quatro e fizeram as tarifas do transporte aéreo subirem (junto com os lucros das empresas) mais do que a inflação.

Vale lembrar que a delimitação dos mercados relevantes no transporte aéreo aqueles nos quais uma operação ou conduta afeta a concorrência, etapa fundamental da análise antitruste (SALGADO, 1997) -, no Brasil, como em todas as demais jurisdições, coincide com as rotas entre aeroportos (ou ligações origem-destino entre cida- 
des), sejam elas nacionais, regionais ou internacionais (TUROLLA, LOVADINE e OLIVEIRA, 2006; SALGADO, VASSALLO e OLIVEIRA, 2010). No caso, a atuação regional das companhias delimita claramente os mercados relevantes como as ligações/rotas operadas pelas companhias em localidades específicas. É possível conjecturar que o fortalecimento do poder de mercado da Azul após a fusão tenha lhe proporcionado recursos para seu salto a mercados internacionais - objetivada na aquisição do controle acionário da companhia aérea portuguesa TAP. Contudo, tal terá se dado, ainda nessa conjectura, à custa de redução do bem-estar do consumidor brasileiro, sem contrapartida em aumento de eficiência - conforme revelam os resultados deste artigo. Ademais, embora ociosa, lembre-se que a lei de defesa da concorrência brasileira tem seu alcance limitado à circunscrição nacional; cabe ao CADE, como autoridade em defesa da concorrência, proteger o mercado nacional, garantindo condições de concorrência que incentivem o compartilhamento dos benefícios gerados no mercado com os consumidores nacionais.

O setor aéreo de transportes de passageiros brasileiro contava com 505 aeronaves e fez 950.387 decolagens no ano de 2012. Conforme vimos nos resultados, os ganhos totais potenciais de eficiência decorrentes da fusão original, no pior dos casos, encontram-se na casa de 1,7\% (seção 6.4), ainda que esse resultado deva ser visto com ressalvas por se tratar apenas de uma parte dos modelos propostos - justamente aqueles que apresentam resultados mais favoráveis a uma eventual aprovação da fusão. A rigor, os resultados apresentados pelos modelos VRS e DRS indicam uma perda de eficiência com a fusão, o que seria um indicativo razoável para sua reprovação.

\section{REFERÊNCIAS}

ANAC - AGÊNCIA NACIONAL DE AVIAÇÃO CIVIL. Anuário do transporte aéreo 2016. Brasília: ANAC, 2017.

ARAÚJO JÚNIOR, A. H. de et al. A eficiência operacional do transporte aéreo brasileiro. Revista Engenharia, São Paulo, v. 582, p. 122-130, Ago. 2007.

AVKIRAN, N. The evidence on efficiency gains: The role of mergers and the benefits to the public. Journal of Banking \& Finance, v. 23, n. 7, p. 991-1013, Jul. 1999.

BAILEY, E. E.; PANZAR, J. C. The contestability of airline markets during the transition to deregulation. Law and Contemporary Problems, Durham, v. 44, n. 1, p. 125-145, Dez. 1981.

BAILEY, E. E.; WILLIAMS, J. R. Sources of economic rent in the deregulated airline industry. The Journal of Law \& Economics, Chicago, v. 31, n. 1, p. 173-202, Abr. 1988.

BANKER, R. D.; CHARNES, A.; COOPER, W. W. Some models for estimating technical and scale inefficiencies in data envelopment analysis. Management Science, v. 30, n. 9, p. 10781092, Set. 1984. 
BAUMOL, W. J.; PANZAR, J. C.; WILLIG, R. D. Contestable markets and the theory of industry structure. New York: HBJ, 1982.

BILOTKACH, V.; LAKEW, P. A. On sources of market power in the airline industry: Panel data evidence from the US airports. Transportation Research Part A: Policy and Practice, v. 59, p. 288-305, Jan. 2014.

BJÖRNERSTEDT, J.; VERBOVEN, F.. Does merger simulation work? Evidence from the Swedish analgesics market. American Economic Journal: Applied Economics, v. 8, n. 3, p. 125-164, Jul. 2016.

BOGETOFT, P.; OTTO, L. Benchmarking with DEA, SFA, and R. New York: Springer, 2011.

BORENSTEIN, S. Hubs and high fares: Dominance and market power in the U.S. airline industry. The RAND Journal of Economics, v. 20, n. 3, p. 344-365, 1989.

BRUECKNER, J. K.; SPILLER, P. T. Economies of traffic density in the deregulated airline industry. The Journal of Law \& Economics, v. 37, n. 2, p. 379-415, Out. 1994.

CAVES, R. E. Air transport and its regulators: an industry study. Cambridge: Harvard University Press, 1962.

CAVES, D. W.; CHRISTENSEN, L. R.; TRETHEWAY, M. W. Economies of density versus economies of scale: why trunk and local service airline costs differ. The Rand Journal Of Economics, Santa Monica, v. 15, n. 4, p. 471-489, Dez. 1984.

CHICAGO TRIBUNE. Airlines carve U.S. into markets dominated by 1 or 2 carriers. Chicago Tribune, 14 jul. 2015. Disponível em: <https://www.chicagotribune.com/business/ct-airlines-local-monopolies-20150714-story.html>. Acesso em: 14 de jul. 2015.

COHEN, A. M.; MAZZEO, M. J. Competition, product differentiation and quality provision: an empirical equilibrium analysis of bank branching decisions. FEDS Working Paper, Washington, n. 2004-46, 2004.

CADE - CONSELHO ADMINISTRATIVO DE DEFESA ECONÔMICA. Decisão Técnica $n^{\circ}$ 257 Superintendência Geral. Versão pública. Brasília: CADE, 2012.

CHARNES, A.; COOPER, W. W.; RHODES, E. Measuring the efficiency of decision-making units. European Journal of Operational Research, Lisboa, v. 2, n. 6, p. 429-444, Nov. 1978.

CHURCH, J. R.; WARE, R. Industrial organization: a strategic approach. New York: McGraw Hill, 2010.

CLEMENTE, F.; GOMES, M. F.M.; LÍRIO, V. S. Análise da eficiência técnica de propriedades citrícolas do Estado De São Paulo. Economia Aplicada, v. 19, n. 1, p. 63-79, Mar. 2015.

CORREIA, T. C. V. D.; MELLO, J. C. C. B. S. de; MEZA, L. A. Eficiência técnica das companhias aéreas brasileiras: um estudo com análise envoltória de dados e conjuntos nebulosos. Revista Produção, Niterói, v. 21, n. 4, p. 676-683, Out. 2011.

CREEL, M.; FARELL, M. Economies of scale in the US airline industry after deregulation: a Fourier series approximation. Transportation Research, St. Louis, v. 37, n. 5, p. 321-336, Nov. 2001.

DEMSETZ, H. Industry structure, market rivalry, and public policy. The Journal of Law \& Economics, Chicago, v. 16, n. 1, p. 1-9, Abr. 1973. 
DEMSETZ, H. "Two systems of belief about monopoly". In: GOLDSCHMID, H. J.; MANN, H. M.; WESTON, J. F. (Eds.). Industrial concentration: The new learning. The 1974 Conference on Industrial Concentration. Boston: Little Brown, 1974, p. 164-184.

DIXIT, A. A model of duopoly suggesting a theory of entry barriers. The Bell Journal of Economics, v. 10, n. 1, p. 20-32, 1979.

EFRON, B. Bootstrap methods: another look at the Jackknife. The Annals of Statistics, Philadelphia, v. 7, n. 1, p. 1-26, Jan. 1979.

EVANS, W. N.; KESSIDES, I. N. Localized market power in the U.S. airline industry. The Review of Economics and Statistics, v. 75, n. 1, p. 66-75, Fev. 1993.

FARRELL, J.; PAUTLER, P. A.; VITA, M. G. Economics at the FTC: retrospective merger analysis with a focus on hospitals. Review of Industrial Organization, v. 35, n. 4, p. 369-385, 31 out. 2009.

FARREL, J.; SHAPIRO, C. Horizontal mergers: an equilibrium analysis. The American Economic Review, Pittsburgh, v. 80, n. 1, p. 107-126, Mar. 1990.

FARREL, J.; SHAPIRO, C. Scale economies and synergies in horizontal merger analysis. Antitrust Law Journal, v. 68, n. 3, p. 685-710, Jan. 2001.

FARRELL, M. J. The Measurement of productive efficiency. Journal of the Royal Statistical Society, Series A, London, v. 120, n. 3, p. 353-290, Jan. 1957.

FAWCETT, S. E.; FARRIS, M. T. Contestable markets and airline adaptability under deregulation. Transportation Journal, State College, v. 29, n. 1, p. 12-24, Abr. 1989.

GARDEN, K. A.; RALSTON, D. E. The x-efficiency and allocative efficiency effects of credit union mergers. Journal of International Financial Markets, Institutions and Money, v. 9, n. 3, p. 285-301, Ago. 1999.

GOETZ, A. R. Deregulation, competition, and antitrust implications in the U.S. airline industry. Journal of Transport Geography, London, v. 10, n. 1, p. 1-19, Mar. 2002.

GUTERRES, M. X.; CORRÊA, A. Estimação de uma função de produção para a indústria do transporte aéreo nacional. In: ENCONTRO NACIONAL DE ENGENHARIA DE PRODUÇÃO, 27., Foz do Iguaçu, PR, Set. 2007, p.1-9.

HALKOS, G. E.; TZEREMES, N. G. Estimating the degree of operating efficiency gains from a potential bank merger and acquisition: A DEA bootstrapped approach. Journal of Banking \& Finance, v. 37, n. 5, p. 1658-1668, Mai. 2013.

JENKINS, H. "Efficiency assessments in European competition policy and practical tools". In: OECD- ORGANIZATION FOR ECONOMIC COOPERATION AND DEVELOPMENT. The role of efficiency claims in antitrust proceedings. Paris: OECD, 2013, p. 245-256.

LEIBENSTEIN, H. Allocative efficiency vs. "X-efficiency". The American Economic Review, Pittsburgh, v. 56, n. 3, p. 392-415, Jun. 1966.

LIU, Z.; LYNK, E. L. Evidence on market structure of the deregulated U.S. airline industry. Applied Economics, London, p. 1083-1092, Set. 1999.

KATZ, M. L. Recent antitrust enforcement actions by the U.S. department of justice: a selective survey of economics issues. Review of Industrial Organization, v. 21, n. 4, p. 373-397, Dez. 2002. 
KAUR, P.; KAUR, G. Impact of mergers on the cost efficiency of Indian commercial banks. Eurasian Journal of Business and Economics, v.3, n. 5, p. 27-50, Mai. 2010.

KWOKA, J. E. "A proposta de fusão da United Airlines/US Airways". In: MATTOS, C. A revolução do antitruste no Brasil 2. A teoria econômica aplicada a casos concretos. São Paulo: Singular, 2008, p. 37-58.

KWOKA, J. E.; POLLITT, M. Do mergers improve efficiency? Evidence from restructuring the U.S. electric power sector. International Journal of Industrial Organization, v. 28, n. 6, p. 645656, Nov. 2010.

MARQUES, R. C.; SILVA, D. Inferência estatística dos estimadores de eficiência obtidos com a técnica fronteira não paramétrica de DEA. Uma metodologia de bootstrap. Investigação Operacional, Lisboa, v. 26, n. 1, p. 89-100, Jan. 2006.

MELLO, J. C. C. B. S. et al. Seleção de variáveis para utilização de análise envoltória de dados como ferramenta multicritério: uma aplicação em educação. In: ENCONTRO NACIONAL DE ENGENHARIA DE PRODUÇÃO, 21., Salvador, BA, set. 2001, p. 1-8.

MELLO, J. C. C. B. S. et al. Análise de envoltória de dados no estudo da eficiência e dos benchmarks para companhias aéreas brasileiras. Pesquisa Operacional, Rio de Janeiro, v. 23, n. 2, p. 325-345, Mai. 2003.

MELLO, J. C. C. B. S. et al.Curso de análise de envoltória de dados In: SIMPÓSIO BRASILEIRO DE PESQUISA OPERACIONAL, 37., Gramado, RS, Set. 2005, p. 2520-2547.

NEVO, A.; WHINSTON, M. D. Taking the dogma out of econometrics: Structural modeling and credible inference. Journal of Economic Perspectives, v. 24, n. 2, p. 69-82, Mai. 2010.

NOLAN, J.; RITCHIE, P.; ROWCROFT, J. "International mergers and acquisitions in the airline industry". In: PEOPLES, J. (Ed.). The economics of international airline transport. Portland: Emerald Group Publishing Limited, 2014, p. 127-150.

OLIVEIRA, M. V. R.; OLIVEIRA, A. V. M. What drives effective competition in the airline industry? An empirical model of city-pair market concentration. Transport Policy, v. 63, p. 165-175, Abr. 2018.

SALGADO, L. H.O Conceito de Mercado Relevante. Revista de Direito Econômico, Brasília, n. 28, p. 37-46, Dez. 1997.

SALGADO, L. H.; VASSALO, M. D.; OLIVEIRA, A. V. M. Regulação, políticas setoriais, competitividade e formação de preços: considerações sobre o transporte aéreo no Brasil. Journal of Transport Literature, v. 4, n. 1, p. 8-48, Jan. 2010.

SAMPAIO, B.; MELO, A. S. Análise da eficiência de companhias aéreas brasileiras. Revista Análise Econômica, Porto Alegre, v. 50, n. 26, p. 223-244, Set. 2008.

SILVA, A. M. A. da. Transporte aéreo doméstico: uma análise econômica para o período recente. Dissertação (Mestrado em Economia) - Escola de Pós-Graduação em Economia, Fundação Getúlio Vargas, Rio de Janeiro, 2001.

SILVA, L. H. S.; DE SOUZA, S. A. Análise econômica da defesa da concorrência no Brasil. Relatório de Pesquisa. Rio de Janeiro: IPEA, 2016.

SIMAR, L.; WILSON, P. W. Sensitivity analysis of efficiency scores: how to bootstrap in non parametric frontier models. Management Science, v. 44, n. 1, p. 49-61, Jan. 1998. 
SPENCE, A. M. Entry, capacity, investment and oligopolistic pricing. The Bell Journal of Economics, v. 8, n. 2, p. 534-544, 1977.

TUROLLA, F. A.; LOVADINE, D.; OLIVEIRA, A. V. M. Competição, colusão e antitruste: estimação da conduta competitiva de companhias aéreas. Revista Brasileira de Economia, Rio de Janeiro, v. 60, n. 4, p. 425-459, Dez. 2006.

WERDEN, G. J.; JOSKOW, A. S.; JOHNSON, R. L. The effects of mergers on price and output: two case studies from the airline industry. Managerial and Decision Economics, v. 12, n. 5, p. 341-352, Out. 1991. 